\title{
Sentidos construídos por atletas de elite sobre a abertura dos jogos olímpicos da juventude de Buenos Aires ${ }^{1}$
}

\section{Signification constructed by elite athletes about the opening of the youth olympic games of Buenos Aires}

\section{Sentidos construidos por atletas de élite sobre la apertura de los juegos olímpicos de la juventud de Buenos Aires}

\author{
iD Adriano Lopes de Souza \\ Universidade Federal do Tocantins, Tocantinópolis, Tocantins, Brasil. \\ e-mail: adriano.lopes@mail.uft.edu.br \\ iD Thayse Mayan Alarcon Ferreira \\ Universidade Federal do Espírito Santo, Vitória, Espírito Santo, Brasil. \\ e-mail: thaysealarcon@gmail.com \\ iD Otávio Tavares \\ Universidade Federal do Espírito Santo, Vitória, Espírito Santo, Brasil. \\ e-mail: tavaresotavio@yahoo.com.br
}

\begin{abstract}
Resumo: O objetivo do presente estudo é compreender os sentidos construídos por atletas de elite sobre a sua experiência de participação na abertura dos Jogos Olímpicos da Juventude de Buenos Aires. Para tanto, o propósito desta investigação apontou para uma abordagem de natureza qualitativa, a partir dos pressupostos teórico-metodológicos da etnometodologia. Os resultados apontaram que a cerimônia de abertura representou para os atletas entrevistados uma espécie de "rito de passagem", compondo-se pela incorporação dos etnométodos próprios a um determinado grupo de elite esportiva. Conclui-se que a produção
\end{abstract}

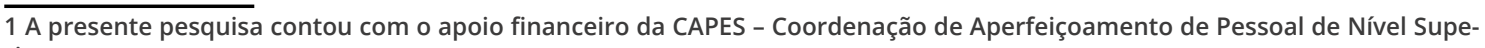
rior. 
de sentidos desses sujeitos foi mediada pela identificação de alguns símbolos e ritos que também aparecem na versão adulta.

Palavras-chave: Jogos Olímpicos da Juventude. Cerimônia de abertura. Sentidos.

Abstract: The objective of the present study is to understand the significations constructed by elite athletes from the experience of participating in the opening of the Youth Olympic Games in Buenos Aires. For the purpose of this investigation pointed to a qualitative approach, based on the theoretical and methodological assumptions of ethnomethodology. The results show that the opening ceremony represented a kind of 'rite of passage' for the athletes interviewed, consisting of the incorporation of ethnomethods belonging to a certain group of the sports elite. It was concluded that the production of the signification of these subjects was mediated by the identification of some symbols and rituals that also appear in the adult version.

Keywords: Youth Olympic Games. Opening Ceremony. Signification.

Resumen: El objetivo del presente estudio es comprender los sentidos construidos por los deportistas de élite sobre la experiencia de participar en la inauguración de los Juegos Olímpicos de la Juventud en Buenos Aires. Para el propósito de esta investigación se apuntó a un abordaje cualitativo, basado en los supuestos teóricos y metodológicos de la etnometodología. Los resultados muestran que la ceremonia inaugural representó una especie de 'rito de paso' para los deportistas entrevistados, consistente en la incorporación de etnometodos pertenecientes a un determinado grupo de la élite deportiva. Se concluyó que sus producciones de sentidos fueron mediadas por la identificación de algunos símbolos y rituales que también aparecen en la versión adulta.

Palabras clave: Juegos Olímpicos de la Juventud. Ceremonia de apertura. Significación.

Submetido em: 09-04-2021

Aceito em: 03-07-2021 
Sentidos construídos por atletas de elite sobre a abertura dos jogos olímpicos da juventude... Adriano Lopes de Souza • Thayse Mayan Alarcon Ferreira • Otávio Tavares

\section{Introdução}

O esporte pode ser considerado um patrimônio cultural da humanidade em virtude da sua significativa dimensão fenomenal, constituindo-se por meio das relações travadas entre diferentes personagens e instituições ao longo de complexos contornos históricos. Dentre eles, destaca-se a influência do Movimento Olímpico e de seu criador - o Barão Pierre de Coubertin - nas formas tradicionais de como praticamos e nos valores que atribuímos à prática esportiva no século XX, em especial, no que se refere à crença de que o esporte aproxima os povos e de que o atleta é ou deve ser um modelo de comportamento (DaCOSTA; TAVARES, 1999; TAVARES, 2007; 2016).

Nesse sentido, o esporte olímpico parece-nos ser merecedor de uma atenção especial, tanto decorrente da sua capacidade de aglutinar atletas com culturas variadas quanto do seu potencial de envolver diferentes esferas da vida social em uma escala planetária (BITENCOURT et al., 2005). Desse modo, os Jogos Olímpicos (JO) podem ser considerados como um dos eventos esportivos mais "superlativos", despertando diferentes interesses (políticos, econômicos, midiáticos, etc.) e contribuindo para produzir narrativas que permitem reconhecer e analisar complexas construções sociais (BILLINGS, 2008; MAGUIRE, 2011).

No entender de DaMatta (2006), por exemplo, os JO refletem a possibilidade de dramatizar a dialética entre o individualismo e a hierarquia, uma vez que nele destaca-se um forte componente individualista, expresso no "atleta-herói". Em contrapartida, os mesmos Jogos também dramatizam coletividades, reunindo ritos de caráter universalista, sobretudo, a partir das cerimônias de abertura e encerramento, bem como ritos cívico-nacionalistas, celebrando os símbolos do país vencedor com o hasteamento da bandeira nacional ao som do seu respectivo hino.

Ora, na esteira desse paradoxo, enveredamos o foco de interesse deste empreendimento investigativo para a cerimônia 
Sentidos construídos por atletas de elite sobre a abertura dos jogos olímpicos da juventude... Adriano Lopes de Souza • Thayse Mayan Alarcon Ferreira • Otávio Tavares

de abertura da modalidade de competição olímpica mais recente criada pelo Comitê Olímpico Internacional (COI). Trata-se dos Jogos Olímpicos da Juventude ou Youth Olympic Games (YOG), cujo principal objetivo consiste não apenas em reunir os jovens atletas de elite - com idades entre 15 e 18 anos - de diferentes cantos do mundo, mas fomentar a celebração de diferentes culturas e o desenvolvimento do espírito olímpico a partir de uma abordagem ética no esporte e na vida, com a promoção dos respectivos princípios e valores olímpicos (COI, 2009). Assim, para efeitos desta pesquisa, o espaço-tempo investigado foi a terceira edição ${ }^{2}$ dos YOG, na cidade de Buenos Aires, em 2018 (YOG-2018).

Nesse contexto, é preciso ter presente que, ao fazermos menção aos jovens atletas de elite, estamos nos referindo notadamente àqueles sujeitos que compõem o esporte de alto rendimento, cuja preparação envolve um conjunto de treinamentos sistematizados em clubes ou similares, com elevada demanda de comprometimento e esforço, objetivando participar de competições de alto nível - desde eventos no âmbito nacional até megaeventos internacionais, como é o caso dos YOG.

A partir de uma revisão sistemática sobre a participação dos jovens atletas de elite em diferentes edições desses Jogos, autores como Souza e Tavares (2020a) identificaram que a experiência valorativa dos sujeitos participantes é marcada, dentre outras coisas, pela oportunidade de tomarem parte na cerimônia olímpica de abertura. Além disso, em outro estudo, tais autores se propuseram a focalizar as práticas espontâneas desses atletas jovens no cotidiano da Vila Olímpica da Juventude dos YOG-2018, cujos resultados apontaram para o caminho da "produtividade" e não da "passividade" na relação com as atividades culturais e educacionais que lhes foram ofertadas, com a consequente produção de sentidos voltados, em especial, para a afirmação da sua identidade enquanto atletas de elite (SOUZA; TAVARES, 2020b).

2 Outras duas edições precederam a realização destes Jogos na capital argentina, as quais foram sediadas nas cidades de Cingapura (2010) e Nanquim (2014), em Singapura e China, respectivamente. Alia-se a estas, duas edições dos YOG de Inverno, sediadas em Innsbruck (2012) e Lillehammer (2016), na Áustria e Noruega, respectivamente. 
Sentidos construídos por atletas de elite sobre a abertura dos jogos olímpicos da juventude... Adriano Lopes de Souza • Thayse Mayan Alarcon Ferreira • Otávio Tavares

Nessa conjuntura, ao considerarmos a importância do cerimonial de abertura na experiência do atleta, bem como a sua capacidade de produzir sentidos que não raras vezes são destoantes da organização institucional do referido megaevento, levantamos a seguinte questão norteadora: qual é a perspectiva dos jovens atletas de elite acerca da sua experiência na cerimônia de abertura dos YOG-2018?

Visto isso, o objetivo do presente estudo foi compreender as maneiras como os jovens atletas de elite relatam as suas experiências na relação com os bens culturais provenientes da abertura protocolar dos YOG-2018. Dessa forma, espera-se que os achados desta investigação científica possam contribuir para trazer pistas sobre as redes de sentidos produzidas pelos referidos atores nesse megaevento, enfocando a sua experiência de participação no respectivo cerimonial de abertura.

\section{Procedimentos metodológicos}

Em consonância com as particularidades do nosso objeto de estudo, a presente pesquisa estruturou-se a partir de uma abordagem qualitativa, cujo interesse perpassa pelos sentidos construídos por sujeitos situados em um determinado contexto, manifestando-se, portanto, na concretude de uma rede complexa de intersubjetividades, interações e interconhecimentos (CHAUVIN; JOUNIN, 2015).

Para tanto, buscamos fundamentação nos pressupostos teórico-metodológicos da etnometodologia (GARFINKEL, 1992; COULON, 1995), com o uso de técnicas como observação e entrevista guiada. Com base na perspectiva etnometodológica, “[...] a interpretação sociológica erudita não deve servir de pretexto para a destruição da informação contextual inicial e indicial produzida pelos atores sociais no cotidiano de suas ações" (SILVA, 2012, p. 193). 
Sentidos construídos por atletas de elite sobre a abertura dos jogos olímpicos da juventude... Adriano Lopes de Souza • Thayse Mayan Alarcon Ferreira • Otávio Tavares

Com isso, nós optamos por dar uma centralidade, aqui, para os relatos produzidos pelos jovens atletas de elite a respeito das suas experiências no contexto da abertura dos YOG-2018. De acordo com Certeau (1994), os relatos têm um papel cotidiano e de demarcar alguns usos do lugar, como uma apropriação narrativa, isto é, como práticas do espaço e do tempo. Destarte, recorremos à técnica de entrevista realizada de forma guiada, na qual recomenda-se que o pesquisador atue como uma espécie de "guia" para o entrevistado, apresentando-lhe de forma paulatina alguns temas a serem tratados no decorrer da entrevista. Ou seja, nesse formato, não se pretende estabelecer uma relação estruturada de perguntas e respostas, mas, antes disso, um processo interativo, conferindo aos entrevistados a possibilidade de relatarem livremente sobre os temas propostos na interação (RICHARDSON, 2015).

O roteiro de conversação foi operacionalizado nos primeiros dias dos YOG-2018, cujo tema principal girava em torno das experiências dos jovens atletas naquele contexto olímpico, focalizando diferentes aspectos da sua participação na cerimônia de abertura, com destaque para a sua apropriação acerca dos rituais olímpicos protocolares (momento do juramento, hasteamento da bandeira e acendimento da Pira Olímpica), bem como a entrada conjunta de todos os atletas. Assim, as entrevistas foram realizadas nos próprios locais dos Jogos, enquanto os respectivos atletas entrevistados aguardavam as suas competições nas áreas livres ou nas arquibancadas, bem como na recepção da Vila Olímpica da Juventude, enquanto eles aguardavam outros membros da comissão técnica e/ou outros jogadores para se dirigirem aos respectivos locais de competição ou, ainda, no momento em que retornavam dos mesmos.

Em consonância com o nosso referencial teórico-metodológico, vale ressaltar que a escolha do número de sujeitos que compuseram o quadro das entrevistas guiadas não buscou atender a critérios de amostragem probabilística, mas deu-se de forma intencional e por conveniência. Além disso, em decorrência de uma 
Sentidos construídos por atletas de elite sobre a abertura dos jogos olímpicos da juventude... Adriano Lopes de Souza • Thayse Mayan Alarcon Ferreira • Otávio Tavares

lacuna identificada na literatura no tocante ao referido megaevento, cujos atletas contemplados como público-alvo foram majoritariamente os atletas norte-americanos e europeus (SOUZA; TAVARES, 2020a), nós optamos por abordar, neste estudo, os jovens atletas sul-americanos que estavam transitando pelos espaços supramencionados e que demonstraram acessibilidade e disponibilidade para participar da presente pesquisa. Com efeito, em virtude do perfil do nosso público-alvo e, sobretudo, do ambiente em que os entrevistamos, nos comprometemos a não delongar esse processo. Em síntese, a duração das entrevistas não excedeu o tempo de 15 minutos. De todo modo, ressalta-se que não foi possível identificar uma brevidade forçosa nas respostas dos atletas, tampouco qualquer influência das suas respectivas comissões técnicas.

Assim, conforme demonstrado no quadro abaixo, compuseram a conjunção de entrevistas guiadas da presente investigação um total de 10 sujeitos, de ambos os sexos, pertencentes a 5 países diferentes e que competiram em modalidades esportivas individuais ou coletivas.

Quadro 1 - Composição das entrevistas guiadas

\begin{tabular}{|c|c|c|c|c|c|}
\hline \multirow{2}{*}{ País } & \multicolumn{2}{|c|}{ Sexo } & \multicolumn{2}{c|}{ Modalidade esportiva } & Sujeitos envolvidos \\
\hline & Masculino & Feminino & Individual & Coletiva & \\
\hline Argentina & 1 & 1 & 2 & - & 2 \\
\hline Bolívia & - & 2 & - & 2 & 2 \\
\hline Brasil & 2 & 1 & 2 & 1 & 3 \\
\hline Chile & - & 2 & 2 & - & 2 \\
\hline Venezuela & 1 & - & 1 & - & 1 \\
\hline TOTAL & 4 & 6 & 7 & 3 & 10 \\
\hline
\end{tabular}

Fonte: Os autores (2021).

Conforme sugerido por Barbot (2015) e Richardson (2015), ao abordar os sujeitos deste estudo, fizemos uma breve autoapre- 
Sentidos construídos por atletas de elite sobre a abertura dos jogos olímpicos da juventude... Adriano Lopes de Souza • Thayse Mayan Alarcon Ferreira • Otávio Tavares

sentação, seguida pela apresentação do nosso objeto de estudo, visando lograr seus respectivos consentimentos. Além disso, nos certificamos de assegurá-los o devido anonimato, identificando-os apenas por suas respectivas nacionalidades. Assim, com a autorização dos referidos sujeitos, registramos os seus relatos em áudio, a fim de serem posteriormente transcritos.

Destarte, para subsidiar as análises e a interpretação do material empírico produzido, recorremos a três conceitos-chave etnometodológicos, os quais foram sistematizados pelo sociólogo francês Alain Coulon, a saber: indicialidade, relatabilidade e noção de membro. O primeiro é representado por uma "margem de incompletude" das palavras, de tal modo que os termos indiciais próprios de determinado grupo - só podem ser compreendidos em circunstâncias contextuais e particulares da sua produção; o segundo conceito-chave refere-se às maneiras como as cenas cotidianas são descritas pelos atores sociais, tornando a realidade que produziram e experienciaram algo compreensível, compartilhável, analisável, relatável; já a noção de membro, por sua vez, transcende a ideia de um membro pertencer socialmente a um determinado grupo, mas da sua capacidade de dominar e compartilhar uma linguagem comum que o agrega a esse grupo, conferindo-lhe, dessa forma, aceitação e reconhecimento (COULON, 1995).

Por fim, cumpre-nos assinalar, ainda, que o presente estudo foi apreciado e aprovado em Comitê de Ética de Pesquisa (CEP) reconhecido, sob o parecer de número 3.066.398.

\section{Resultados e discussão}

No processo analítico, dois termos indiciais emergiram com maior proeminência no tratamento dos dados a partir das entrevistas guiadas, cujos sentidos produzidos dependem sobremaneira do conhecimento prévio a respeito do seu contexto local. Desse modo, ressalta-se que o ensejo de observarmos in loco a cerimônia 
Sentidos construídos por atletas de elite sobre a abertura dos jogos olímpicos da juventude... Adriano Lopes de Souza • Thayse Mayan Alarcon Ferreira • Otávio Tavares

de abertura dos YOG-2018 foi imprescindível para acumularmos uma rede de conhecimentos das circunstâncias práticas correlatas ao uso desses termos indiciais (e contextuais), possibilitando-nos compreendê-los para além do seu sentido estritamente semântico, tal como veremos a seguir.

\subsection{TERMO INDICIAL 1: "início de uma meta"}

Ao focalizarmos a temática da cerimônia de abertura nas entrevistas guiadas, identificamos que este momento parece significar um marco para os jovens atletas que convivem com um paradoxo que transita entre encarar a sua inédita e irrepetível participação nos YOG-2018 como uma oportunidade para divertir-se, fazer contatos, conhecer novas culturas e construir amizades; e, por outro lado, encará-la como uma vitrine propícia para ganhar visibilidade e notoriedade nas suas competições, utilizando esse megaevento como uma oportunidade de amadurecer técnica e psicologicamente para se firmar nas suas respectivas modalidades esportivas, com a consequente (e iminente) participação nos JO (tal como já aconteceu com outros atletas, conforme descrevemos adiante). Sobre esse ponto, foram produzidos relatos que sugerem determinado deslocamento entre tais eixos, conforme ilustrado a seguir: Bom, significou o início de uma meta. Um sonho que nesse momento estava começando a cumprir-se (ATLETA DA VENEZUELA, entrevista, 12 out. 2018, grifo nosso).

É um sonho estar aqui. Me fez sentir muita emoção, me fez sentir que estava aqui, como: "Sim! estou aqui, é de verdade!" (ATLETA DA BOLÍVIA, entrevista, 10 out. 2018).

É um sonho na vida de qualquer atleta que, tipo, tem uma meta. Quem é atleta, almeja isso (ATLETA DO BRASIL, entrevista, 12 out. 2018).

Têm-se como corolário desses relatos que tais atores começaram a perceberem-se mais claramente como atletas olímpicos a 
Sentidos construídos por atletas de elite sobre a abertura dos jogos olímpicos da juventude... Adriano Lopes de Souza • Thayse Mayan Alarcon Ferreira • Otávio Tavares

partir do rito protocolar de abertura atinente aos YOG-2018. Tratase, portanto, do momento em que se desenvolve o progressivo domínio da linguagem comum ao grupo no qual o sujeito está imbricado. Assim, ao descrever que tal experiência consistia na realização de um sonho comum/compartilhado e, ao mesmo tempo, no "início de uma meta", os referidos atletas de elite evidenciam que tal cerimônia de abertura representa uma espécie de "rito de passagem", compondo-se pela incorporação dos etnométodos próprios a este grupo específico, a partir dos quais afirma-se o sentimento de pertencimento com seus respectivos membros (COULON, 1995). Aqui, ratifica-se a mesma intenção tacitamente partilhada entre eles, indicando que os YOG-2018 resultam em uma importante porta de entrada para vir a participar dos JO.

No estudo realizado com diferentes atletas brasileiros que participaram da edição dos JO de Atlanta em 1996, por exemplo, Tavares (1998) identificou que a participação nestes Jogos representou, para estes sujeitos, a maior e mais importante experiência da sua carreira esportiva. Segundo este autor, os principais motivos resultam basicamente do grau de excelência deste megaevento, sua periodicidade (quadrienal) e por sua histórica e reconhecida tradição, de tal modo que nada se compara, por exemplo, às cerimônias de abertura e encerramento destes Jogos (TAVARES, 1998). Aliás, algo semelhante ao que o COI prevê para os YOG.

No que tange à correlação manifesta entre esses dois megaeventos, Souza, Mataruna-Dos-Santos e Tavares (2019, p. 234) parecem corroborar a perspectiva dos jovens atletas entrevistados, uma vez que estes autores fazem menção a um detalhe importante:

[...] os YOG são como uma porta de preparação para os Jogos Olímpicos convencionais. Tal percepção ganha validação nos dados quando observarmos que nos Jogos Rio 2016 foram conquistadas 80 medalhas ( 19 de ouro, 33 de prata e 28 de bronze) por atletas que anteriormente representavam seus países nos YOG (SOUZA; MATARUNA-DOS-SANTOS; TAVARES, 2019, p. 234). 
Sentidos construídos por atletas de elite sobre a abertura dos jogos olímpicos da juventude... Adriano Lopes de Souza • Thayse Mayan Alarcon Ferreira • Otávio Tavares

Aliás, dentre esses atletas, vale a pena especificar o caso emblemático do canoísta baiano Isaquias Queiroz, que, após ter participado dos YOG de Cingapura 2010 - sem conquistar nenhuma medalha -, foi aos JO do Rio 2016 e acabou se tornando o maior medalhista brasileiro em uma única edição destes Jogos, denotando que o pico de carreira de um atleta, de fato, não é (ou pelo menos não deveria ser) nos YOG.

Destarte, no caso deste estudo, nota-se que o fato de considerar os JO como uma meta a ser alcançada ajuda a justificar a valorização e a importância que os referidos sujeitos atribuem aos YOG-2018, considerando a oportunidade de participar destes Jogos como um sonho que estava se realizando naquele momento e, simultaneamente, como uma etapa em direção à referida meta de médio/longo prazo.

Ora, por um lado, os nossos dados concordam com o estudo de Peters e Schnitzer (2015), ao apontarem que os atletas de diferentes nacionalidades perceberam os YOG de Inverno de 2012 - em Innsbruck - como o maior evento em que eles tinham participado até aquele ano; por outro lado, tais dados contrastam com o estudo realizado por Krieger (2012), que, após entrevistar oito atletas alemães que participaram dos YOG de Cingapura 2010, identificou que sete deles subestimaram este megaevento, alegando que ele sequer representava o auge do seu calendário esportivo anual, ao utilizarem, para tanto, o pretexto de que o mesmo não acarretava modificações significativas no ranqueamento mundial (KRIEGER, 2012).

Diante do exposto, parece-nos que a percepção dos referidos atletas alemães pautava-se sobremaneira nos resultados esportivos de curto prazo, diferindo-se, desse modo, dos atletas sul-americanos que compuseram o presente estudo. Ademais, vale comentar que tais apreciações opostas em relação aos YOG indicam a necessidade da realização de novas pesquisas com o mesmo público-alvo para termos um quadro mais claro acerca das atitudes dos jovens atletas em relação a esse megaevento esportivo. 
Sentidos construídos por atletas de elite sobre a abertura dos jogos olímpicos da juventude... Adriano Lopes de Souza • Thayse Mayan Alarcon Ferreira • Otávio Tavares

Com efeito, de forma análoga ao que tradicionalmente ocorre com a versão adulta, identificamos em nossas observações in loco que os YOG-2018 também celebraram um conjunto de rituais ${ }^{3}$ e símbolos olímpicos na sua cerimônia de abertura. Dentre eles, destacam-se o momento do Juramento, o acendimento da Pira e o hasteamento da Bandeira Olímpica, cujos respectivos significados foram colocados como pontos de pauta na realização das referidas entrevistas guiadas.

Assim, no olhar dos sujeitos desta pesquisa, identificamos que tais rituais são significativamente competentes para comunicar-Ihes a mensagem de que, naquele exato momento, estava sendo constituída uma determinada comunidade de excelência, evidenciando mais uma vez a "noção de membro" (COULON, 1995) em relação a uma determinada elite esportiva, conforme demonstrado abaixo:

É um juramento para que tomemos isto seriamente, de que não é um jogo, uma copa interna do teu país ou de escola, um interescolar (ATLETA DA BOLÍVIA, entrevista, 10 out. 2018, grifo nosso).

Aquele fogo lá [na Pira Olímpica] mostra que agora é pra valer né? Tipo, você está lá no meio dos melhores, representando o Brasil e todo mundo lá no país torcendo por nós. É muito bom! (ATLETA DO BRASIL, entrevista, 12 out. 2018, grifo nosso).

De que em verdade começou, porque desde que chegamos na vila foi tudo brincadeira, conhecer pessoas. Depois de acender a chama [na Pira Olímpica] foi como: "sim! agora começou, amanhã começa a competição" (ATLETA DA BOLÍVIA, entrevista, 10 out. 2018, grifo nosso).

3 Refere-se a um sistema cultural de comunicação simbólica, expressando o que está presente no cotidiano de um determinado grupo, incluindo o discernimento do arcabouço de ideias e de valores comuns a seus integrantes (PEIRANO, 2003). 
Sentidos construídos por atletas de elite sobre a abertura dos jogos olímpicos da juventude... Adriano Lopes de Souza • Thayse Mayan Alarcon Ferreira • Otávio Tavares

Acho que é o mais importante que um atleta pode viver, porque é a primeira vez nos jogos, então é bem significativa a bandeira [Olímpica] (ATLETA DO CHILE, entrevista, 11 out. 2018, grifo nosso).

Portanto, com base na perspectiva dos sujeitos desta pesquisa, pode-se conjecturar que a abertura dos YOG-2018 parece ter cumprido o que Tavares (2003) denomina de função "quase-religiosa" das cerimônias e dos símbolos olímpicos, os quais reificam-se como um ritual moderno e secular, capazes de engendrar um sentimento coletivo de envolvimento e compromisso, elevando os Jogos ao nível de uma experiência singular na vida dos atletas participantes. De fato, tais elementos fornecem subsídios para que os JO - e, por extensão, os YOG - possam sobressair-se a qualquer outro evento esportivo que os respectivos atletas já tenham participado anteriormente.

Esse dado vai ao encontro do estudo realizado por Krieger e Kristiansen (2016) junto a 12 atletas alemães e 10 atletas noruegueses que participaram dos YOG de Cingapura 2010 ou dos YOG de Inverno de Innsbruck 2012. Conforme identificado pelos autores, a cerimônia de abertura foi vista por esses sujeitos como uma das suas experiências mais marcantes nos respectivos megaeventos, principalmente em virtude do fomento de alguns símbolos olímpicos que histórica e tradicionalmente compõem a abertura dos JO (KRIEGER; KRISTIANSEN, 2016), tais como os acima descritos pelos atletas sul-americanos entrevistados.

\subsection{TERMO INDICIAL 2: “não ir com tua bandeira”}

Ainda no que diz respeito à sua experiência na cerimônia de abertura dos YOG-2018, identificamos que os jovens atletas fizeram diferentes menções sobre o momento em que foram apresentados para o público presente como protagonistas desse me- 
Sentidos construídos por atletas de elite sobre a abertura dos jogos olímpicos da juventude... Adriano Lopes de Souza • Thayse Mayan Alarcon Ferreira • Otávio Tavares

gaevento, a partir das quais emergiu a expressão indicial "não ir com tua bandeira".

Sobre esse ponto, é importante destacar que enquanto na cerimônia de abertura dos JO cada delegação desfila sob o signo da sua bandeira nacional, nos YOG, por sua vez, todos os atletas são convidados a desfilar conjuntamente (tal como aconteceu nos YOG-2018), numa tentativa institucional de fomentar maiores trocas interculturais entre eles (KRIEGER; KRISTIANSEN, 2016). Todavia, ao tratar desse tema, os jovens atletas sul-americanos lançaram mão de um emaranhado de discursos que nos permitem identificar a produção de sentidos polissêmicos a respeito do referido momento/fomento, considerando-o divertido, estranho e/ou desorganizado, conforme demonstrado abaixo:

Ou seja, não ir com tua bandeira? Por um lado, senti que foi bem divertido, bem enérgico [todos entrarem juntos]. Por outro lado, não se notava quem era quem, de onde eram, só se via uma massa de pessoas entrando (ATLETA DA BOLÍVIA, entrevista, 10 out. 2018, grifo nosso).

Sei lá, eu achei estranho entrar todo mundo junto e misturado daquele jeito, mas eu tava lá com meu time (ATLETA DO BRASIL, entrevista, 12 out. 2018).

Na realidade, foi um pouco esquisito que só passara a bandeira e que não passara conosco. Todas as delegações [juntas], mas, tudo bem (ATLETA DA VENEZUELA, entrevista, 12 out. 2018).

Bom, eu creio que poderia ter sido melhor, mas, a nossa equipe esteve bem representada (ATLETA DA ARGENTINA, entrevista, 10 out. 2018). 
Sentidos construídos por atletas de elite sobre a abertura dos jogos olímpicos da juventude... Adriano Lopes de Souza • Thayse Mayan Alarcon Ferreira • Otávio Tavares

Eu creio que o ponto baixo é que não souberam entrar os atletas. Estávamos todos muito apertados, tinha muita gente e não tinha nem cadeiras, acho que foi isso o que menos gostei. Então, pensando nos outros [JO], onde entram por delegação, é bem bonito. Aqui foi muito desorganizado (ATLETA DO CHILE, entrevista, 11 out. 2018).

Percebe-se que ao tornar as suas experiências relatáveis, explicáveis, os jovens atletas descrevem as maneiras pelas quais lidam com as interações promovidas na abertura do referido evento, indicando os seus respectivos sentidos. Trata-se da manifestação do conceito de relatabilidade (COULON, 1995). Assim, constatamos nos relatos dos jovens atletas entrevistados que tal estranhamento acarretado pela entrada diferenciada se justifica, sobretudo, em virtude da expectativa que eles tinham de desfilarem nessa cerimônia com o porte das suas respectivas bandeiras nacionais.

Segundo argumentado por DaMatta (2006), os JO devem ser considerados como um grande ritual que dramatiza, simultaneamente, coletividades e individualidades, por meio das cerimônias de abertura e encerramento e das cerimônias de premiação, respectivamente, buscando o equilíbrio entre o universalismo e o nacionalismo. Com isso, pode-se depreender, no caso deste estudo, que o uso da expressão indicial "não ir com tua bandeira" sugere o atravessamento do seu campo semântico (deslocar-se sem o porte da sua bandeira), denotando que houve uma certa dificuldade dos sujeitos entrevistados na mediação do referido equilíbrio. Afinal, a coletividade celebrada naquele momento envolvia a totalidade de atletas jovens, independente das cores de sua bandeira nacional. Isto, por sua vez, conflui para a demonstração do universalismo, conforme ilustrado pela bandeira olímpica com os cinco anéis entrelaçados.

Ademais, identificamos nas interações discursivas dos/com nossos entrevistados que o fato de buscarem estar junto/próximo dos seus pares enquanto "time", seja referente à sua modalidade esportiva (especialmente se coletiva) ou à sua nação como um 
Sentidos construídos por atletas de elite sobre a abertura dos jogos olímpicos da juventude... Adriano Lopes de Souza • Thayse Mayan Alarcon Ferreira • Otávio Tavares

todo, representou, para alguns deles, uma espécie de atenuante ao estranhamento decorrente da entrada conjunta e misturada. A partir desse movimento, eles produziram uma sutil desconstrução de um espaço que havia sido institucionalmente organizado em prol do fomento das interações entre os jovens atletas de diferentes culturas. A este respeito, Certeau (1994) argumenta:

Os consumidores produzem "trajetórias indeterminadas", aparentemente desprovidas de sentido porque não são coerentes com o espaço construído, escrito e pré-fabricado onde se movimentam. São frases imprevisíveis num lugar ordenado pelas técnicas organizadoras de sistemas. [...] essas "trilhas" continuam heterogêneas aos sistemas onde se infiltram e onde esboçam as astúcias de interesses e de desejos diferentes (CERTEAU, 1994, p. 97).

Assim, no que se refere aos interesses e desejos não atendidos, percebemos que os jovens atletas relataram não apenas determinada desorganização/confusão no momento em que foram apresentados, mas, também, o fato de passarem muito tempo em pé olhando para o Obelisco. Um dos atletas acrescentou, inclusive, o seu entendimento a respeito do desconforto gerado para o público presente em decorrência do mesmo motivo.

\begin{abstract}
Eu creio que as pessoas ficaram um pouco entediadas no final porque não haviam cadeiras para sentar-se e estavam a muito tempo em pé. E bom, as primeiras coisas que se fizeram penduradas no obelisco estiveram boas, mas depois não, porque as pessoas se cansaram de estar olhando o tempo todo só para o obelisco (ATLETA DA ARGENTINA, entrevista, 10 out. 2018).
\end{abstract}

Em Souza, Mataruna-Dos-Santos e Tavares (2019) observa-se que, a despeito da plasticidade da transmissão televisiva, por exemplo, o evento de abertura dos YOG-2018 reuniu uma caótica 
Sentidos construídos por atletas de elite sobre a abertura dos jogos olímpicos da juventude... Adriano Lopes de Souza • Thayse Mayan Alarcon Ferreira • Otávio Tavares

aglutinação de pessoas, sem espaço para sentar, com dificuldades de entendimento do espetáculo e sem orientação alguma do que estava por acontecer, de tal modo que somente os atletas tiveram uma vista privilegiada do palco.

Entretanto, em observância à relatabilidade dos sujeitos desta pesquisa, pode-se articular que tal localização privilegiada que eles ocupavam não parece ter sido suficiente para atender aos seus interesses e, consequentemente, isentar a cerimônia de abertura dos YOG-2018 das referidas críticas, muito embora eles a tenham considerada significativa, em especial, a partir da identificação de alguns símbolos que também aparecem nos JO.

\section{Considerações finais}

Amparados pelo aporte teórico-metodológico da etnometodologia, foi possível captar no presente estudo que a abertura protocolar dos YOG-2018 parece significar, para os jovens atletas entrevistados, uma espécie de "rito de passagem", reificando, dessa maneira, a constituição de uma determinada comunidade de excelência naquele espaço-tempo, o que, por sua vez, traz à tona a "noção de membro", tal como é apresentada por Coulon (1995).

Sabe-se que as cerimônias olímpicas são uma parte constituinte do caráter singular dos JO, em especial, por veicular um conjunto de ritos, símbolos e uma multiplicidade esportiva (coisas que campeonatos mundiais não possuem), fazendo destes Jogos um evento diferenciado e superior para muitos atletas olímpicos (TAVARES, 1998).

Ora, tal particularidade dos JO também parece-nos aplicar-se perfeitamente aos YOG. No caso da edição de Buenos Aires, por exemplo, foi possível constatar que a produção de sentidos de parte dos atletas participantes foi mediada pela identificação de alguns símbolos e ritos que também fazem parte da abertura dos JO convencionais. Com efeito, isso ajuda a justificar o estranha- 
Sentidos construídos por atletas de elite sobre a abertura dos jogos olímpicos da juventude... Adriano Lopes de Souza • Thayse Mayan Alarcon Ferreira • Otávio Tavares

mento dos referidos atletas jovens no que se refere ao desfile coletivo sem o porte das suas respectivas bandeiras nacionais, indo de encontro à entrada protocolar de cada delegação - conforme ocorre na versão adulta - e, consequentemente, às expectativas iniciais desses sujeitos.

Ademais, percebe-se no contexto dos YOG-2018 que a participação no cerimonial de abertura constituiu-se para os referidos atletas como uma experiência significativa, cuja respectiva produção de sentidos atravessa o caráter festivo e espetacularizado desse megaevento esportivo.

Em tempo, destaca-se que os resultados desta pesquisa contribuem para melhor compreendermos a rede de produção de sentidos por parte dos jovens atletas sul-americanos, mais especificamente no tocante ao cerimonial de abertura do referido megaevento. Destarte, isso permite-nos avançar em relação à lacuna identificada na literatura científica no que tange aos YOG, cujos atletas contemplados como público-alvo são majoritariamente os atletas norte-americanos e europeus.

Em contas finais, cumpre-nos reconhecer que as escolhas teórico-metodológicas que fizemos rechaça qualquer pretensão de captarmos a totalidade das redes de sentidos dos jovens atletas de elite sobre o contexto investigado. Portanto, sugere-se a realização de novos estudos capazes de contemplar, por exemplo, outros grupos de atletas sul-americanos, tanto para melhor compreendê-las, quanto para compará-las com as perspectivas dos atletas de outros continentes.

\section{Referências}

BARBOT, J. Conduzir uma entrevista de face a face. In: PAUGAM, S. (coord.). A pesquisa sociológica. Petrópolis: Vozes, 2015, p. 102-123. 
Sentidos construídos por atletas de elite sobre a abertura dos jogos olímpicos da juventude... Adriano Lopes de Souza • Thayse Mayan Alarcon Ferreira • Otávio Tavares

BILLINGS, A. Olympic Media: Inside the biggest show on television. Routledge: Critical Studies in Sport, 2008.

BITENCOURT, F. G. et al. Ritual Olímpico e os Mitos da Modernidade: implicações midiáticas na dialética universal/local. Pensar a Prática, Goiânia, v. 8, n. 1, p. 21-36, 2005.

CERTEAU, M. A invenção do cotidiano: as artes de fazer. Petrópolis: Vozes, 1994.

CHAUVIN, S.; JOUNIN, N. A Observação direta. In: PAUGAM, S. (coord.). A pesquisa sociológica. Petrópolis: Vozes, 2015. p. 124140.

COI. Youth Olympic Games. Lausanne: COI, 2009. Disponível em: https://www.olympic.org/news/what-is-yog. Acesso em: 15 ago. 2020.

COULON, A. Etnometodologia. Petrópolis: Vozes, 1995.

DaCOSTA, L. P; TAVARES, O. Introdução. In: DACOSTA, L. P; TAVARES, O. (eds.). Estudos Olímpicos. Rio de Janeiro: Editora Gama Filho. 1999. p. 6-12.

DaMATTA, R. Em torno da dialética entre igualdade e hierarquia: notas sobre as imagens e representações dos Jogos Olímpicos e do futebol no Brasil. In: DaMATTA, R. A bola corre mais que os homens: duas copas, treze crônicas e três ensaios sobre futebol. Rio de Janeiro: Rocco, 2006, p. 172-204.

GARFINKEL, H. Studies in Ethnomethodology. New York: Blackwell Pub, 1992.

KRIEGER, J.; KRISTIANSEN, E. Ideology or reality? The awareness of Educational aims and activities amongst German and Norwegian participants of the first summer and winter Youth Olympic Games. Sport in Society, Londres, v. 19, n. 10, p. 1503-1517, 2016.

KRIEGER, J. Fastest, highest, youngest? Analysing the athlete's experience of the Singapore Youth Olympic Games. International Review for the Sociology of Sport, Loughborough, v. 48, n. 6, p. 706-719, 2012. 
Sentidos construídos por atletas de elite sobre a abertura dos jogos olímpicos da juventude... Adriano Lopes de Souza • Thayse Mayan Alarcon Ferreira • Otávio Tavares

MAGUIRE, J. A. The global media sports complex: key issues and concerns. Sport in society, Londres, v. 14, n. 7-8, p. 965-977, 2011.

PEIRANO, M. (org.). Rituais ontem e hoje. Rio de Janeiro: Jorge Zahar, 2003.

PETERS, M.; SCHNITZER, M. Athletes' Expectations, Experiences, and Legacies of the Winter Youth Olympic Games Innsbruck 2012. Journal of Convention \& Event Tourism, Londres, v. 16, n. 2, p. 116-144, 2015.

RICHARDSON, R. J. Pesquisa social: métodos e técnicas. 3 ed. São Paulo: Atlas, 2015.

SILVA, C. A. F. Pequeno vocabulário de etnometodologia. In: SILVA C. A. F.; VOTRE, S. J. (orgs.). Etnometodologias. Rio de Janeiro: HP Comunicação Editora, 2012. p. 187-196.

SOUZA, A. L.; TAVARES, O. A experiência educacional dos atletas nos Jogos Olímpicos da Juventude: uma revisão sistemática.

Movimento, Porto Alegre, v. 26, n. 39, p. 1-14, 2020a.

SOUZA, A. L.; MATARUNA-DOS-SANTOS, L. J.; TAVARES, O. OS Jogos Olímpicos da Juventude: Buenos Aires, Cidade Olímpica. In: RUBIO, Kátia. (org.). Do pós ao neo Olimpismo: esporte e movimento olímpico no século XXI. São Paulo: Kepos, 2019. p. 231-246. SOUZA, A. L.; TAVARES, O. Entre as atividades promovidas e o consumo produtivo: análise das práticas dos jovens atletas de elite nos jogos olímpicos da juventude. Motrivivência, Florianópolis, v. 32, n. 63, p. 1-26, 2020 b.

TAVARES, O. Esporte, movimento olímpico e democracia: 0 atleta como mediador. 2003. Tese (Doutorado em Educação Física) - Faculdade de Educação Física, Universidade Gama Filho, Rio de Janeiro, 2003.

TAVARES, O. Mens Fervida in Corpore Lacertoso? As atitudes dos atletas olímpicos brasileiros diante do Olimpismo. Dissertação (Mestrado em Educação Física) - Faculdade de Educação Física, Universidade Gama Filho. Rio de Janeiro, 1998. 
Sentidos construídos por atletas de elite sobre a abertura dos jogos olímpicos da juventude... Adriano Lopes de Souza • Thayse Mayan Alarcon Ferreira • Otávio Tavares

TAVARES, O. Valores Olímpicos no século XXI. In: RUBIO, K. et al. Ética e compromisso social nos estudos olímpicos. Porto Alegre: EDIPUCRS, 2007. p. 181- 202.

TAVARES, O. Valores em Jogo: Educação em valores por meio do esporte - educação olímpica. Vitória, no prelo, 2016.

\section{Publisher}

Universidade Federal de Goiás. Faculdade de Educação Física e Dança. Publicação no Portal de Periódicos UFG. As ideias expressadas neste artigo são de responsabilidade de seus autores, não representando, necessariamente, a opinião dos editores ou da universidade. 